\title{
Study of iron deficiency anemia with thrombocytosis in association with serum erythropoietin levels
}

\author{
Ramu $\mathbf{R}^{1}$, Narayana Murthy $\mathbf{C}^{2}$ \\ ${ }^{1}$ Dr. Ramu R, Assistant Professor, ${ }^{2}$ Dr. Narayana Murthy C, Professor \& Head, both authors are affiliated with \\ Department of Pathology, Basaveshwara Medical College Hospital \& Research Center, Chitradurga, Karnataka, India.
}

Address for Correspondence: Dr. Ramu R, Assistant Professor, Department of Pathology, Basaveshwara Medical College Hospital \& Research Center, SJM Campus, Chitradurga 577501, Karnataka, Email: drramuroyal@ gmail.com

\begin{abstract}
Aim: To evaluate the correlation of iron deficiency anemia with thrombocytosis in correlation with serum erythropoietin levels. Introduction: Thrombocytosis is a common hematologic finding that can present as an incidental finding and can lead to a great diagnostic challenge. Thrombocytosis can be caused due to autonomous or as a reactive overproduction secondary to infections, iron deficiency anemia, malignancies. Erythropoietin (EPO) is the primary regulator of erythrocyte production and also affects thrombopoiesis and platelet function. The mechanism leading to thrombocytosis in cases of iron deficiency anemia (IDA) remains unclear. Hence, this study was undertaken to evaluate correlation between IDA with thrombocytosis and serum EPO levels. Materials \& Methods: A total of 50 patients of all the age groups attending out-patient and inpatient departments of Basaveshwara Medical College Hospital and Research center, Chitradurga suspected of having microcytic hypochromic anemia on initial hematological investigations were included for study over a period from January 2016 to august 2016. Relevant investigations like peripheral smear study, serum iron studies and serum erythropoietin levels were subsequently performed. Results: Majority 52\% (n=26) had anemia between 7-9.9 gm/dl of which 57.69\% ( $\mathrm{n}=15)$ cases had platelet count between 5-7 lakhs/cu.mm, 34.61\% ( $\mathrm{n}=9)$ cases had moderate thrombocytosis and 7.69\% $(\mathrm{n}=2)$ cases had severe thrombocytosis. Out of 50 cases in the present study $76 \%$ $(n=38)$ cases had significant increase in the levels of serum erythropoietin while $24 \%(n=12)$ cases had normal serum erythropoietin. Conclusion: From the present study, it may be concluded that erythropoietin would play a significant role in causing thrombocytosis in patients with iron deficiency anemia.
\end{abstract}

Key words: Erythropoietin, Iron deficiency anemia, Thrombocytosis.

\section{Introduction}

Thrombocytosis is a common hematologic finding that can present as an incidental finding and can lead to a great diagnostic challenge. Thrombocytosis can be caused due to autonomous overproduction or as a reactive overproduction secondary to infections, iron deficiency anemia, malignancies $[1,2]$. It has been proposed that the thrombocytosis in iron deficiency anemia (IDA) may be caused by chronic blood loss [3]. Even mild fall the in platelet count has also been observed mostly in severe degree of IDA [4]. Erythropoietin (EPO) is the primary regulator of erythrocyte production and is required for the survival and proliferation of committed erythroid progenitor

Manuscript received: $24^{\text {th }}$ February 2017

Reviewed: $2^{\text {nd }}$ March 2017

Author Corrected: $9^{\text {th }}$ March 2017

Accepted for Publication: $15^{\text {th }}$ March 2017 cells. EPO enhances the rate of formation of red blood cells in the bone marrow and also several evidences suggest that it also affects thrombopoiesis and platelet function [5].

The mechanism leading to thrombocytosis in cases of iron deficiency anemia remains unclear. However few studies have shown that certain thrombopoietic cytoikines like thrombopoietin, $\mathrm{IL}-6$ as a cause of thrombocytosis in IDA [6,7]

Due to paucity of studies done on serum erythropoietin levels and thrombocytosis in IDA, this study was undertaken to evaluate correlation between iron deficiency anemia with thrombocytosis and serum erythropoietin levels. 


\section{Materials and Methods}

Inclusion Criteria: Patients of all age groups presenting with pallor, weakness, fatigue in out-patient and inpatient departments for common illnesses and diagnosed to be due to iron deficiency were included in the study.

Exclusion Criteria: Patients presenting with anemia due to causes other than iron deficiency and thrombocytosis due to causes other than iron deficiency anemia were excluded from the study.

Sampling method: A convenient sample of 50 patients was randomly selected. Patients of all the age groups presenting with pallor, weakness, fatigue in out-patients and in-patients of Basaveshwara Medical College Hospital and Research center, Chitradurga were included for study from January 2016 to August 2016.

Sample collection: The selected patients were subjected to a detailed history and thorough clinical examination. Relevant investigations were done as per individual case requirement. Under aseptic precautions, $5 \mathrm{ml}$ of venous blood was withdrawn of which $2 \mathrm{ml}$ was preserved in an EDTA bulb, $3 \mathrm{ml}$ in a plain bulb for iron studies and serum erythropoietin. From EDTA blood sample complete blood count was done by automated cell counter and the peripheral smear slides of the samples were prepared and stained with
Leishmann's stain to counter check the analyser results. Patients with low hemoglobin levels, MCV <80fl and with peripheral smear showing microcytic hypochromic anemia were selected and their serum was assayed for iron studies and erythropoietin levels using chemiluminescent immunoassay.

The patients were followed up after one month of iron supplementation.

\section{Statistical analysis:}

a) The data obtained was compiled and analysed using statistical package for social services (version 20).

b) Pearson correlation test was applied to study the correlation between hemoglobin percentage, platelet count and serum erythropoietin levels.

Anemia was graded as mild, moderate and severe based on hemoglobin concentration: [4]

a) Mild (Hb 10-11 gm/dl), b) Moderate (Hb7-9.9 gm/dl), c) Severe $(\mathrm{Hb}<7 \mathrm{gm} / \mathrm{dl})$.

Thrombocytosis was also graded as: [4]

a) Mild:5-7 lakhs/cu.mm (b) Moderate-7-9 lakhs/cu. mm (c) Severe - >9 lakhs/cu.mm

\section{Results}

In the present study, $40 \%(\mathrm{n}=20)$ were male patients and $60 \%(\mathrm{n}=30)$ were female patients. Majority of the patients $(24 \%, n=12)$ were aged between $21-30$ years, of which females were $26.6 \%(n=8)$ and in males $25 \%(n=5)$ mainly belonged to 41-50 years of age. (Table 1)

Table-1: Age and sex wise distribution in cases of iron deficiency anemia with thrombocytosis.

\begin{tabular}{|c|c|c|c|}
\hline Age (in years) & Number of cases & Male & Female \\
\hline $1-10$ & $6(12 \%)$ & $3(15 \%)$ & $3(10 \%)$ \\
\hline $11-20$ & $4(8 \%)$ & $1(5 \%)$ & $8(26.6 \%)$ \\
\hline $21-30$ & $12(24 \%)$ & $4(20 \%)$ & $6(20 \%)$ \\
\hline $31-40$ & $9(18 \%)$ & $3(15 \%)$ & $3(10 \%)$ \\
\hline $41-50$ & $8(16 \%)$ & $5(25 \%)$ & $4(13.3 \%)$ \\
\hline $51-60$ & $6(12 \%)$ & $2(10 \%)$ & $3(10 \%)$ \\
\hline$>60$ & $5(10 \%)$ & $2(10 \%)$ & $\mathbf{3 0}(\mathbf{6 0} \%)$ \\
\hline
\end{tabular}

In the present study, majority of the $52 \%(\mathrm{n}=26)$ cases had moderate anemia between $7-9.9 \mathrm{gm} / \mathrm{dl}, 28 \%(\mathrm{n}=14)$ cases had severe anemia of less than $7 \mathrm{gm} / \mathrm{dl}$ and $20 \%(\mathrm{n}=10)$ cases had mild anemia between $10-11 \mathrm{gm} / \mathrm{dl}$. (Table 2) 
Table-2: Showing distribution of cases in relation to severity of anemia.

\begin{tabular}{|c|c|c|}
\hline Severity of anemia $(\mathbf{g m} / \mathbf{d l})$ & No of patients & Percentage \\
\hline Mild $(\mathrm{Hb} 10-11)$ & 10 & 20 \\
\hline Moderate $(\mathrm{Hb} 7-9.9)$ & 26 & 28 \\
\hline Severe $(\mathrm{Hb}<7)$ & 14 & 100 \\
\hline Total $(\mathrm{n}=50)$ & 50 & 28 \\
\hline
\end{tabular}

In the present study, majority 54\% $(\mathrm{n}=27)$ cases had mild thrombocytosis, $36 \%(\mathrm{n}=18)$ cases had moderate thrombocytosis and $10 \%(n=5)$ cases had severe thrombocytosis. (Table 3 )

Table-3: Showing distribution of cases in relation to grades of thrombocytosis.

\begin{tabular}{|c|c|c|}
\hline Grades of thrombocytosis & No of patients & Percentage \\
\hline $\begin{array}{c}\text { Mild Thrombocytosis } \\
\text { (5-7 lakhs/cu.mm) }\end{array}$ & 27 & 54 \\
\hline $\begin{array}{c}\text { Moderate Thrombocytosis } \\
\text { (7 - 9 lakhs/cu.mm) }\end{array}$ & 18 & 36 \\
\hline $\begin{array}{c}\text { Severe Thrombocytosis } \\
\text { (>9 lakhs/cu.mm) }\end{array}$ & 5 & 10 \\
\hline Total $(\mathbf{n}=\mathbf{5 0})$ & $\mathbf{5 0}$ & $\mathbf{1 0 0}$ \\
\hline
\end{tabular}

The study showed most of the cases $52 \%(\mathrm{n}=26)$ had anemia between 7-9.9gm/dl of which $57.69 \%(\mathrm{n}=15)$ cases had mild thrombocytosis, $34.61 \%(\mathrm{n}=9)$ cases had moderate thrombocytosis and $7.69 \%(\mathrm{n}=2)$ cases had severe thrombocytosis. There was a statistically significant and positive correlation between hemoglobin percentage and platelet count. $(r=0.915$, p value $<0.001$, Sig) $($ Table 4)

Table-4: Showing status of anemia in relation to thrombocytosis.

\begin{tabular}{|c|c|c|c|}
\hline Anemia (gm/d) & $\begin{array}{c}\text { Mild Thrombocytosis } \\
\text { (5-7 lakhs/cu.mm) }\end{array}$ & $\begin{array}{c}\text { Moderate } \\
\text { Thrombocytosis } \\
\text { (7 - 9 lakhs/cu.mm) }\end{array}$ & $\begin{array}{c}\text { Severe Thrombocytosis } \\
\text { (>9 lakhs/cu.mm) }\end{array}$ \\
\hline Mild (Hb 10-11) $\mathrm{n}=10$ & $6(60 \%)$ & $4(40 \%)$ & 0 \\
\hline Moderate $(\mathrm{Hb} 7-9.9) \mathrm{n}=26$ & $15(57.69 \%)$ & $9(34.61 \%)$ & $3(7.69 \%)$ \\
\hline Severe $(\mathrm{Hb}<7) \mathrm{n}=14$ & $6(42.85 \%)$ & $5(35.71 \%)$ & $5(10 \%)$ \\
\hline Total $(\mathrm{n}=50)$ & $27(54 \%)$ & $18(36 \%)$ & \\
\hline
\end{tabular}

$\mathrm{r}=0.915, \mathrm{p}$ value $<0.001, \mathrm{Sig}$

The study also showed a statistically significant and positive correlation between platelet count and serum erythropoietin levels. $(r=0.693$, p value $<0.001$, Sig). Out of 50 cases in the present study $76 \%(n=38)$ cases had significant increase in the levels of serum erythropoietin while $24 \%(n=12)$ cases had normal serum erythropoietin. The results showed a statistically significant correlation between hemoglobin percentage, platelet count and serum erythropoietin levels. ( $\mathrm{r}=-$ 0.873 , p value $<0.001$, Sig) (Table 5)

Table-5: Status of anemia with thrombocytosis in relation to serum erythropoietin levels.

\begin{tabular}{|c|c|c|}
\hline \multirow{2}{*}{ Anemia with thrombocytosis } & \multicolumn{2}{|c|}{ Serum erythropoietin levels ( 5.4 - 31mIU/ml) } \\
\cline { 2 - 3 } & Increased & Normal \\
\hline Mild $(\mathrm{Hb} 10-11) \mathrm{n}=10$ & 6 & 8 \\
\hline Moderate $(\mathrm{Hb} 7-9.9) \mathrm{n}=26$ & 18 & - \\
\hline Severe $(\mathrm{Hb}<7) \mathrm{n}=14$ & 14 & $12(24 \%)$ \\
\hline Total $(\mathbf{n}=\mathbf{5 0})$ & $38(76 \%)$ & \\
\hline
\end{tabular}

$r=-0.873, p$ value $<0.001$, Sig 


\section{Discussion}

Iron deficiency anemia (IDA) is one of the most prevalent micronutrient deficiency in India and one of leading causes of anemia. Iron in the body is recycled between the functional and storage pools. Free iron is highly toxic and it is sequestered by binding in the storage pool tightly to either ferritin or hemosiderin. IDA can result from dietary deficiency, impaired absorption, increased requirement and chronic blood loss that eventually lead to a defect in hemoglobin synthesis and decreased amount of hemoglobin. Chronic blood loss may in the form of external hemorrhage or bleeding into genital, urinary and gastrointestinal tracts [8]. Cellular proliferation is also reduced in iron deficiency leading to decrease in red cell numbers.

There is significant ineffective erythropoiesis and immature erythroid cells formed are very defective and are rapidly destroyed. Some of the cross transfusion studies have reported that the survival of circulating erythrocytes is shortened as a result of intracorpuscular defect [9]. In Iron deficiency anemia the globin protein synthesis is reduced and each cell that is produced contains less hemoglobin leading to microcytosis and hypochromia.

The initial negative iron balance would be compensated by storage forms (ferritin and hemosiderin) that maintain normal hemoglobin, serum iron and transferrin saturation. With progressive depletion of these storage forms, first there is lowering of serum iron and transferrin saturation levels without producing anemia and anemia develops only when iron stores are completely depleted and accompanied by low serum iron, ferritin and transferrin saturation levels [8].

Along with the changes in RBC indices, IDA is also known to cause mild to moderate thrombocytosis. Reactive thrombocytosis may soon resolve after iron supplement but may occasionally result in clinical manifestations such as thrombotic events. The pathomechanism of reactive thrombocytosis in patients with iron deficiency is so far unknown.

Few of the studies have reported that the causes of thrombocytosis in moderate IDA may be attributed to increased rate of inflow of precursor cells into the megakaryocyte division with an increased rate of outflow, shortening of megakaryocyte maturation, stem-cell deflect due to inhibition of erythropoiesis leading to increased production of other pluripotent cells as a hemostatic compensatory mechanism [10,11].

However few of the recent studies have also reported that increased levels of endogenous erythropoietin would stimulate megakaryopoiesis in IDA eventually resulting in thrombocytosis. [10,12]. IDA is associated with irritability, palpitations, dizziness, breathlessness, headache and fatigue. Atrophy of the lingual papillae is one of the most common epithelial changes seen in iron deficiency. The diagnosis of IDA includes a complete blood count that shows reduction in red cell indices, peripheral smear study which shows microcytosis, hypochromia and ansiopoikilocytosis. Red cell distribution width (RDW) is increased in IDA and is useful in differentiating from thalassemia trait conditions in which RDW is normal. Bone marrow shows mild to moderate erythroid hyperplasia where in normoblasts appear small with scanty cytoplasm and irregular ragged borders [9].

The aim of the study was to evaluate the correlation of iron deficiency anemia with thrombocytosis in correlation with serum erythropoietin levels and the results have shown $76 \%(n=38)$ cases have elevated serum erythropoietin levels ( $r=-$ 0.873, p value<0.001, Sig). The platelet count returned to normal levels in 40 cases after one month of iron supplementation while 10 cases had mild degree of thrombocytosis. Thrombopoietin is a vital hormone that regulates megakaryocyte differentiation and proliferation in association with various cytokines like IL-1,IL-6, IL-11 [13,14]. Bilic and Bilic reported that an amino acid sequence homology between thrombopoietin and erythropoietin may explain thrombocytosis in children with IDA [15].

A study done by Tania O \& Alka B [4] on hematological abnormalities of Platelet Count in Children with Iron Deficiency Anemia have found that among total of 200 patients, 49 i.e $24.5 \%$ cases were found to have thrombocytosis of which $75.5 \%$ of the cases had mild thrombocytosis closely relating to the present study where in $54 \%$ of cases had mild thrombocytosis. Among total 49 cases with thrombocytosis, platelet count returned to normal after one month of iron therapy in 45 cases while rest all 4 cases had mild degree of thrombocytosis in concordance with the present study where in platelet count in 40cases returned to normal levels and 10 cases had mild thrombocytosis (Table 6) 
Research Article

Table-6: Comparison of studies of anemia with thrombocytosis.

\begin{tabular}{|c|c|c|c|c|c|c|}
\hline \multirow{2}{*}{$\begin{array}{c}\text { Severity of } \\
\text { Anemia } \\
\text { (gm/dl) }\end{array}$} & \multicolumn{2}{|c|}{$\begin{array}{l}\text { Mild Thrombocytosis } \\
\text { (5-7 lakhs/cu.mm) }\end{array}$} & \multicolumn{2}{|c|}{$\begin{array}{l}\text { Moderate Thrombocytosis } \\
\text { (7 - } 9 \text { lakhs/cu.mm) }\end{array}$} & \multicolumn{2}{|c|}{$\begin{array}{c}\text { Severe Thrombocytosis } \\
\text { (>9 lakhs/cu.mm) }\end{array}$} \\
\hline & $\begin{array}{c}\text { Tania O \& } \\
\text { Alka B }\end{array}$ & Present study & $\begin{array}{c}\text { Tania O \& Alka } \\
\text { B }\end{array}$ & $\begin{array}{l}\text { Present } \\
\text { study }\end{array}$ & $\begin{array}{c}\text { Tania O \& } \\
\text { Alka B }\end{array}$ & $\begin{array}{l}\text { Present } \\
\text { study }\end{array}$ \\
\hline $\begin{array}{l}\text { Mild (Hb 10- } \\
\text { 11) }\end{array}$ & 1 & 6 & 1 & 4 & 0 & 0 \\
\hline $\begin{array}{l}\text { Moderate }(\mathrm{Hb} \\
7-9.9)\end{array}$ & 28 & 15 & 7 & 9 & 2 & 2 \\
\hline Severe $(\mathrm{Hb}<7)$ & 8 & 6 & 1 & 5 & 1 & 3 \\
\hline Total & $37(75.5 \%)$ & $27(54 \%)$ & $9(18.4 \%)$ & $18(36 \%)$ & $3(6.1 \%)$ & $5(10 \%)$ \\
\hline
\end{tabular}

A study was done by Akan $\mathrm{H}$ et al [7] in women with iron deficiency anemia with thrombocytosis in correlation with thrombopoietin, erythropoietin (EPO), leukemia inhibitory factor, interleukin-6 and interleukin-11 levels. In their study there were no changes in thrombopoietic cytokines except for EPO where high EPO levels were associated with high platelet counts correlating with the present study where $76 \%$ of the cases showed increased EPO levels associated with increased platelet count, suggesting that EPO increases platelet counts. They have also suggested that reactive thrombocytosis and iron deficiency relationship is more complex as few patients with iron deficiency anemia and elevated erythropoietin levels do not present with thrombocytosis. In vitro studies have shown that EPO enhances mouse megakaryocyte maturation [16] and acted synergistically with thrombopoietin to promote the production of megakaryocyte precursors from CD34-positive cells [17]. As mentioned by some of the studies above, erythropoietin might share few biochemical properties with thrombopoietin and cause thrombocytosis in patients with iron deficiency anemia.

Results found by Ashok kumar et al show that $45 \%$ of the cases had a statistically significant association between iron deficiency anemia and thrombocytosis in pediatric age group in rural population study. However, their study had very limited explanation regarding the pathophysiology of thrombocytosis [6].

According to Kadikoylu G et al study, thrombocytosis was detected in $27.9 \%$ cases and have stated that there was an inverse relationship between platelet count and iron saturation wherein decrease iron saturation might stimulate megakaryopoiesis further causing thrombocytosis [10].

\section{Conclusion}

To conclude, as there is scarce published date available on the studies done on iron deficiency anemia with thrombocytosis in association with erythropoietin levels involving all the age groups, this study was undertaken to know the relation between erythropoietin levels, hemoglobin percentage and platelet count.

From the present study, it may be concluded that erythropoietin would play a significant role in causing thrombocytosis in patients with iron deficiency anemia.

Whenever a patient presents with iron deficiency anemia with thrombocytosis, it would be helpful if serum erythropoietin levels are estimated to prevent occurrence of any thrombotic complications.

Funding: Nil, Conflict of interest: None initiated, Permission from IRB: Yes

\section{References}

1. Abha Chandna et al. Iron deficiency anemia with thrombocytosis: a diagnostic challenge. International J. of Healthcare and Biomedical Research. 2014; 03(1) : 43-46.

2. Buss DH, Cashell AW, O'Connor ML, Richards F 2nd, Case LD. Occurrence, etiology, and clinical significance of extreme thrombocytosis: a study of 280 cases. Am J Med. 1994 Mar;96(3):247-53.

3. Anemias of Disordered Iron Metabolism and Heme Synthesis. In: Mckenzie. Clinical Laboratory Hematology. New Jersey: Pearson Prentice Hall; 2004: 189-219.

4. Tania O, Alka B. To Study Hematological Abnormalities of Platelet Count in Children With Iron 


\section{Research Article}

Deficiency Anemia In India. Intl.J of scientific research. 2016; 5(4): 90-95.

5. Stohlawetz PJ, Dzirlo L, Hergovich N, Lackner E, Mensik C, Eichler HG, Kabrna E, Geissler K, Jilma B. Effects of erythropoietin on platelet reactivity and thrombopoiesis in humans. Blood. 2000 May 1;95 (9): 2983-9.

6. Dr. Ashok kumar $\mathrm{C}$ et al. Incidence of thrombocytosis in iron deficiency anemia in pediatric age group in rural population. Indian Journal of Basic and Applied Medical Research.2013; 3(1): 45-49.

7. Akan H, Güven N, Aydogdu I, Arat M, Beksaç M, Dalva K. Thrombopoietic cytokines in patients with iron deficiency anemia with or without thrombocytosis. Acta Haematol. 2000;103(3):152-6.

8. Red blood cell and bleeding disorders.In:Kumar V, Abbas AK, Fausto N, Aster JC eds. Robbins and Cotran Pathologic Basis of Disease. $8^{\text {th }}$ ed. New Delhi: Elsevier; 2010, p.639-76

9. Goodnough LT, Nemeth E. Iron deficiency and related disorders. In: Greer JP, Arber DA, Glader B, List AF, Means RT(Jr), Paraskevas F, Rodgers GM, eds. Wintrobe's Clinical Hematology. $13^{\text {th }}$ ed. China: Lippincott Williams \& Wilkins; 2014, p.617-642 .

10. Kadikoylu G, Yavasoglu I, Bolaman Z, Senturk T. Platelet parameters in women with iron deficiency anemia. J Natl Med Assoc. 2006 Mar;98(3):398-402.
11. Choi SI, Simone JV. Platelet production in experimental iron deficiency anemia. Blood. 1973 Aug; 42 (2):219-28.

12. Beguin Y. Erythropoietin and platelet production. Haematologica. 1999 Jun; 84(6):541-7.

13. Kaushansky K. Thrombopoietin and the hematopoietic stem cell. Blood. 1998 Jul 1;92(1):1-3.

14. Alexandrakis MG, Passam FH, Moschandrea IA, Christophoridou AV, Pappa CA, Coulocheri SA, Kyriakou DS. Levels of serum cytokines and acute phase proteins in patients with essential and cancerrelated thrombocytosis. Am J Clin Oncol. 2003 Apr;26 (2):135-40.

15. Bilic E, Bilic E. Amino acid sequence homology of thrombopoietin and erythropoietin may explain thrombocytosis in children with iron deficiency anemia. J Pediatr Hematol Oncol. 2003 Aug; 25(8):675-6.

16. Ishibashi T, Koziol JA, Burstein SA. Human recombinant erythropoietin promotes differentiation of murine megakaryocytes in vitro. J Clin Invest. 1987;79:286-289.

17.Papayannopoulou T, Brice M, Farrer D, Kaushansky K. Insights into the cellular mechanisms of erythropoietin-thrombopoietin synergy. Exp Hematol. $1996 ; 24: 660-669$.

\section{How to cite this article?}

Ramu R, Narayana Murthy C. Study of iron deficiency anemia with thrombocytosis in association with serum erythropoietin levels. Trop J Path Micro 2017;3(1):71-76.doi: 10.17511/jopm.2017.i1.13. 